\title{
A GUIDE TO THE IDENTIFICATION OF THE ANOPHELINE MOSQUITOES OF SRI LANKA. III. PUPAE
}

\author{
F.P. AMERASINGHE \\ Department of Zoology, University of Peradeniya, Peradeniya.
}

(Received: 19 April 1995; accepted: 11 August 1995)

\begin{abstract}
An lllustrated key is provided for the identification of the pupal stages of 21 of the 22 species of anopheline mosquitoes occurring in Sri Lanka, for which this life stage has been previously described. The species discussed are: Anopheles (Anopheles) aitkenii James, An. (Ano.) barbirostris Van der Wulp, An. (Ano.) barbumbrosus Strickland \& Chowdhury, An. (Ano.) gigas Giles var. refutans Alcock, An. (Ano.) interruptus Puri, An. (Ano.) nigerrimus Giles, An. (Ano.) peditaeniatus Leicester, An. (Ano.) peytoni Kulasekera, Harrison \& Amerasinghe, An. (Cellia) aconitus Dönitz, An. (Cel.) annularis Van der Wulp, An. (Cel.) culicifacies Giles, An. (Cel.) elegans James, An. (Cel.) jamesii Theobald, An. (Cel.) karwari (James), An. (Cel.) maculatus Theobald, An. (Cel.) pallidus Theobald, An. (Cel.) pseudojamesi Strickland \& Chowdhury, An. (Cel.) subpictus Grassi, An. (Cel.) tessellatus Theobald, An. (Cel.) varuna Iyengar, and An. (Cel.) vaguis Dönitz. The pupa of one species, Anopheles (Anopheles) reidi Harrison, is unknown.
\end{abstract}

Key words: Anopheles, key for identification, pupae, Sri Lanka.

\section{INTRODUCTION}

Mosquitoes of the genus Anopheles are vectors of human and animal malaria, and are also involved in the transmission cycles of filarial nematodes and viruses. ${ }^{1-3}$ Recentresearch in Sri Lanka has.shown that although An. culicifacies Giles (species B) is the major vector of malaria, several other species may be involved in seasonal or local transmission in different parts of the country. ${ }^{4-6}$ Thus, accurate identification of anopheline species is becoming increasingly important in the context of local malaria entomology. As part of an ongoing study on the taxonomy of Sri Lankan mosquitoes, illustrated keys for the identification of adult and larval stages of local anophelines have been published previously. ${ }^{7,8}$

Anopheline pupal taxonomy, however, has received relatively little attention in the Indian subcontinent. Pupae possess stable taxonomic characters that are readily visible under high power on slide-mounted exuviae. However, these characters are more difficult to visualize on whole pupae under dissecting microscopes, due primarily to pupal shape, colouration, and the generally inconspicuous nature of taxonomically important setae. Pupae often constitute the smaller proportion of field-collected immatures (relative to larvae), and field workers usually go through the laborious process of rearing out adults from collected pupae in order to establish species identity. However, pupae that die during rearing and those directly killed and preserved in the field cannot be identified by such means. The routine identification of field collected pupae is of some importance, as apart from purely taxonomic considerations, quantitative data based on this life stage can provide better estimates of adult production from breeding habitats than those derived from larval stages alone. This is 
because mortality within different larval stages, and in the larval-pupal transformation can be extremely high. Following upon the publication of keys for the identification of adults and larvae, ${ }^{7,8}$ the present paper provides an illustrated key to the pupae of Sri Lankan anophelines, so as to complete the series on the taxonomy of the local anopheline species.

\section{METHODS AND MATERIALS}

The following 21 species are included in the key: Anopheles (Anopheles) aitkenii James, An. (Ano.) barbirostris Van der Wulp, An. (Ano.) barbumbrosus Strickland \& Chowdhury, An. (Ano.) gigas Giles var. refutans Alcock, An. (Ano.) interruptus Puri, An. (Ano.) nigerrimus Giles, An. (Ano.) peditaeniatus Leicester, An. (Ano.) peytoni Kulasekera, Harrison \& Amerasinghe, An. (Cellia) aconitus Dönitz, An. (Cel.) annularis Van der Wulp, An. (Cel.) culicifacies Giles, An. (Cel.) elegans James, An. (Cel.) jamesii Theobald, An. (Cel.) karwari (James), An. (Cel.) maculatus Theobald, An. (Cel.) pallidus Theobald, An. (Cel.) pseudojamesi Strickland \& Chowdhury, An. (Cel.) subpictus Grassi, An. (Cel.) tessellatus Theobald, An. (Cel.) varuna Iyengar, and An. (Cel.) vagus Dönitz. The pupa of An. (Ano.) reidi Harrison is unknown, and is not included in the key.

The primary taxonomic literature references used in constructing the key were the works of Harrison \& Scanlon ${ }^{1}$ (for subgenus Anopheles), Reid ${ }^{3}$ and Christophers $^{9}$ (for subgenera Anopheles and Cellia), and Harrison ${ }^{10}$ (for the Myzomyia series of subgenus Cellia). These works contained taxonomic descriptions of pupae, as well as species-group related keys for the southeast Asian or Oriental regions, that allowed the formulation of key steps for most of the species occurring in Sri Lanka. In addition, Mendis et al. ${ }^{11}$ and Kulasekera et al. ${ }^{12}$ were consulted for detailed descriptions of An. elegans and An. peytoni, respectively.

Pupal stages (slide-mounted exuviae with associated larval and adult stages) of local Anopheles collected by the Smithsonian Institution's Medical Entomology Project (MEP), as well as field material collected by the author and deposited at the Department of Zoology, University of Peradeniya, were also examined during the study. These included An. barbirostris, An. nigerrimus, An. peditaeniatus, An. peytoni, An. aconitus, An. annularis, An. culicifacies, An. elegans, An. jamesii, An. subpictus, An. varuna, and An. vagus. Specimens of $A n$. tessellatus were obtained from a colony maintained at the Institute of Fundamental Studies (IFS), Kandy. This material was used to check taxonomic characters used in the key, as well as to formulate the key characters used for the identification of An. subpictus and An. vagus (pupae of which have been incorrectly separated previously) ${ }^{3}$, as well as An. elegans and An. tessellatus which have not been treated in previous pupal keys. ${ }^{3}$

Pupal chaetotaxy designations used herein follow Harbach \& Knight. ${ }^{13}$ The illustrations were drawn by the author partly from original material (in the case of species available for direct examination) and partly adapted from previous works. ${ }^{1,3}$ They are diagrammatic representations of characters used in the key, meant as a guide to those unfamiliar with the morphology and chaetotaxy of 
mosquito immature stages, and follow the standard conventions established for mosquito taxonomic publications. ${ }^{13}$ The following points of clarification are made for those unfamiliar with aspects of the modern terminology and conventions that may be found in the key and illustrations: (i) Pupal setal numbers are denoted by arabic numerals and abdominal segment numbers by roman numerals; (ii) The meatal cleft of the trumpet is always located on the inner (mesal) side, and the secondary cleft (if present) located on the outer (lateral) side; (iii) The two borders of the paddle are referred to as lateral (outer) and mesal (inner) borders; (iv) The refractile border of the paddle refers to the region of the lateral border that usually bears marginal serrations ("paddle teeth"), and is refractile to light; (v) the term "mesad" refers to the inner (mesal) side, and "laterad" to the outer (lateral) side of any structure.

\section{KEY TO ANOPHELINE PUPAE}

1. Trumpet with longest axis more or less vertical to stem; rim of trumpet simple, without secondary cleft (Fig. 1a)

Trumpet with longest axis transverse to stem; rim of trumpet with or without secondary cleft (Fig. 1b) (Subgenus Anopheles; Laticorn section; Myzorhynchus series; barbirostris and hyrcanus gps.)

2(1). Trumpet very broad and rounded; transverse axis about as long as vertical; a very large species (Fig. 2a) (Subgenus Anopheles; Angusticorn section; Anopheles series; lindesayi gp.) gigas

Trumpet not so broad, vertical axis longer than transverse;

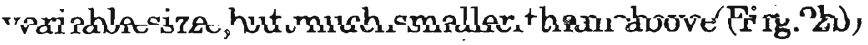
3

3(2). Paddle broad, 1.5 or less times as long as wide; seta 5-V-VII usually no stouter than 1-V-VII; male genital lobes with apical knobs (Fig. 3a) (Subgenus Cellia)

Paddle elongate, 1.6 or more times as long as wide; if not elongate then seta 5-V-VII much stouter than 1-V-VII; male genital lobes not ending in knob (Fig. 3b) (Subgenus Anopheles; Angusticorn section; Anopheles and Lophoscelomyia series)

4(3). Seta 1-Pa short, 0.15 or less length of lateral margin of paddle; 9-V-VII usually less than 0.35 length of lateral margin of their respective segments (Fig. 4a) (Neomyzomyia series)

Seta 1-Pa long, 0.25 or more length of lateral margin of paddle, curved, sinuate or hooked at tip; 9 -V-VII usually 0.35 or more length of lateral margin of their respective segments (Fig. 4b) 
5(4). Seta 1-VI,VII 3-5 branched; seta 9-V-VII, 0.15 or less length of lateral margin of respective segments; genital lobe with clearly defined knobs (Fig. 5a) tessellatus

Seta 1 -VI,VII usually single; seta 9 -V-VII 0.25 or more length of lateral margin of respective segments; genital lobe with indistinctly defined knobs (Fig. 5b) elegans

6(4). Seta 9-I simple, rarely branched, long, usually twice or more length of lateral margin of segment I (Fig. 6a) (Pyretophorus series)

Seta 9-I simple or branched, shorter to slightly longer than lateral margin of segment I (Fig. 6b)

7(6). Seta 9-V-VII with distinctly blunt tips (Fig. 7a) subpictus

Seta 9-V-VII with distinctly sharp pointed tips (Fig. 7b) vagus

8(6). Seta 9-IV usually 0.67 or more length of $9-\mathrm{V}$, with same tapering sharp pointed shape as $9-\mathrm{V}$; 1 -II with 8 or more branches (Fig. 8a) (Myzomyia series)

Seta 9-IV 0.15 to 0.67 length of $9-\mathrm{V}$, broader with more rounded apex than 9-V; 1-II with $2-10$ branches, usually less than 8 (Fig. 8b) (Neocellia series) 11

9(8). Seta 1-V-VII simple; seta 7-VI,VII same length or slightly shorter than 9-VI,VII, approximately 0.35 to 0.70 length of segment VI, VII lateral margins; paddle fringe not extending mesad of seta 1-Pa (Fig. 9a) culicifacies

Seta 1-V-VII usually 2-5 branched; seta 7-VI,VII much longer than 9-VI,VII, equal to or slightly longer than segment VI, VII lateral margins; paddle fringe extending mesad of seta 1-Pa (Fig. 9b)

10(9). Paddle fringe spicules mesad of seta 1-Pa short, widely spaced, approximately 0.5 length of spicules just laterad of $1-\mathrm{Pa}$, mesal spicules not extendingto mesal angle of paddle; trumpet pinna distally rounded, venter convex at apex; sum of branches of both setae 1-III, 14-32; sum of branches of both setae 5-III, 9-22 (Fig. 10a) aconitus 
Paddle fringe spicules mesad of seta 1-Pa long, closely spaced, equal in length to spicules just laterad of 1-Pa, mesal spicules extending to mesal angle of paddle; trumpet pinna distally flattened, venter concave at apex; sum of branches on both setae 1-III, 31-39; sum of branches on both setae 5-III, 22-37 (Fig. 10b) varuna

11(8). Seta 9-IV usually less than 0.1 length of lateral margin of segment, less than 0.25 length of $9-\mathrm{V}$ (Fig. 11a) karwari

Seta 9-IV 0.2 or more length of lateral margin of segment, 0.25 or more length of $9-\mathrm{V}$ (Fig. 11b)

12(11). Seta 1-Pa, unstraightened, about $0: 33$ or more length of paddle; fringe spicules extend mesad of seta 1-Pa (Fig. 12a) maculatus

Seta 1-Pa, unstraightened, less than 0.33 length of paddle; fringe spicules do not extend mesad of seta 1-Pa (Fig. 12b) 13

13(12). Seta 2-VII usually simple; trumpet meatus about 0.33 trumpet length (Fig. 13a) .pseudojamesi

Seta 2-VII usually $2-4$ branched; trumpet meatus about 0.25 trumpet length (Fig. 13b). 14

14(13). Seta 9-I usually triple; lower refractile border of paddle with non-filamentous spicules (Fig. 14a) annularis

Seta 9-I simple or bifid; lower refractile border of paddle with filamentous spicules (Fig. 14b) 15

15(14). Seta 1-Pa strongly coiled (Fig. 15a) .jamesii

Seta 1-Pa hooked, but not coiled (Fig. 15b) pallidus

16(3). Trumpet without meatal cleft; seta 1-Pa with 2-5 branches from midpoint; phytotelmic habitats (Fig. 16a) (Lophoscelomyia series; asiaticus gp.) interruptus

Trumpet with deep meatal cleft; seta 1-Pa simple; ground water habitats (Fig. 16b) (Anopheles series, aitkenii gp.) 
17(16). Seta 1-IV with 2-5 branches; seta 9-IV with blunt, rounded tip; paddle refractile margin long (0.6) (Fig. 17a) aitkenii

Seta 1-IV with 5-9 branches; seta 9-IV with sharp tip; paddle refractile margin short (0.4-0.5) (Fig. 17b) peytoni

18(1). Opening of trumpet narrow, very transverse when viewed from above; seta 1-VII a strong tuft of 15-50 branches (Fig. 18a) (barbirostris gp.)

Opening of trumpet more expanded when viewed from above; seta 1-VII a weaker tuft of 1-7 branches (Fig. 18b) (hyrcanus gp.)

19(18). Trumpet without secondary cleft, but with thickened seam; abdominal seta 9 dark brown to black; seta 9-VII 6-8 times as long as thick (Fig. 19a) barbumbrosus

Trumpet with secondary cleft, without seam; abdominal seta 9 yellow to light brown; seta 9-VII 4-6 times as long as thick (Fig. 19b) barbirostris

20(18). Trumpet with thickened saw-toothed areas on rim; seta 9-VIII branching reduced or absent (Fig. 20a) peditaeniatus

Trumpet without thickened saw-toothed areas, but with dark border area delineating thin, uniform rim; seta 9-VIII with well developed branches (Fig. 20b) nigerrimus

(The pupa of $A n$. (Ano.) reidi of the barbirostris group is unknown. However, based on group characteristics it should key out to the barbirostris group at step 18).

Figures 1-20 are diagrammatic representations of key characters, numbered in accordance with the key steps. Abbreviations are as follows: GL = genital lobe, $\mathrm{MC}=$ meatal cleft, $\mathrm{MP}=$ metanotal plate, $\mathrm{Pa}=$ paddle, $\mathrm{S}=$ seam, $\mathrm{SC}=$ secondary cleft, $\operatorname{Tr}=$ trumpet. 
FIG 1a

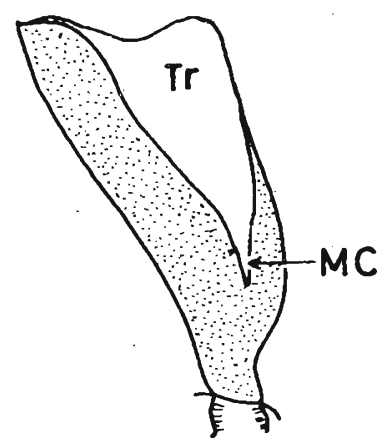

FIG 1b

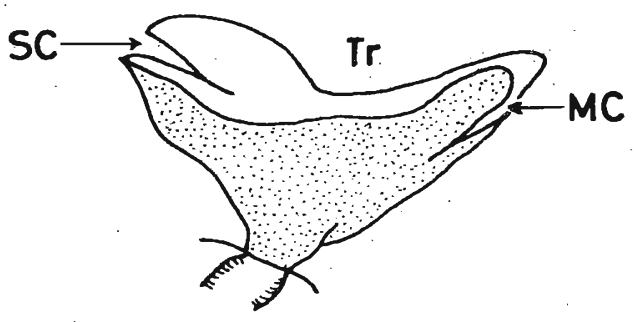

Figure 1a,b: Lateral view of angusticorn and laticorn trumpets.

FIG 2a

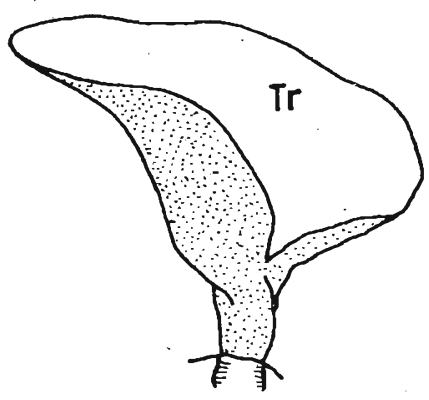

FIG 2b

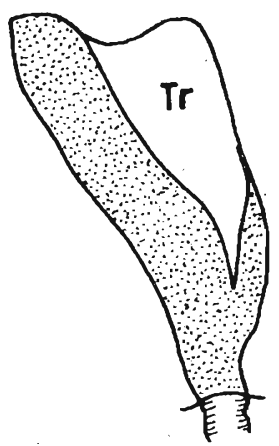

Figure 2a,b: Lateral view of two angusticorn trumpets.

FIG 3a

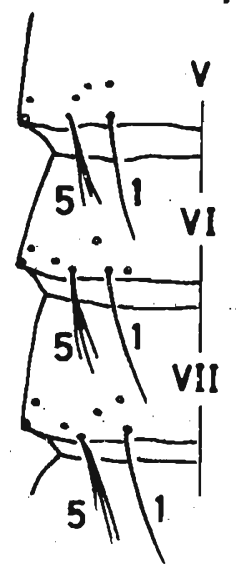

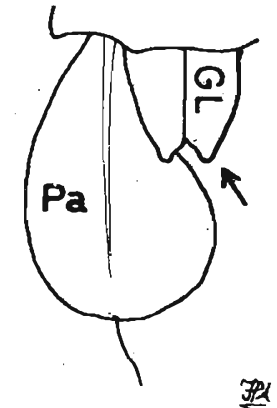

洫
FIG 3b

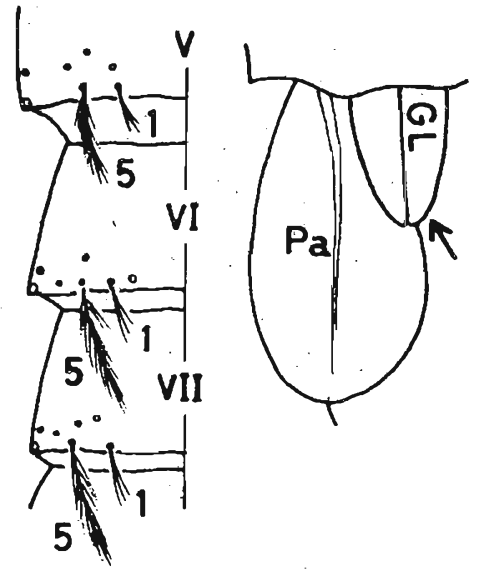

Figure 3a,b: Dorsal view of abdominal segments V-VII to show seta 1,5-V-VII, and ventral view of genital lobe. 
FIG $4 a$

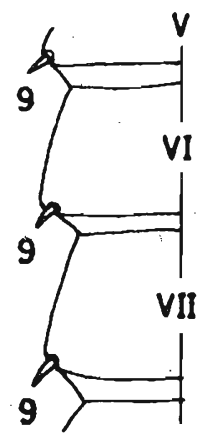

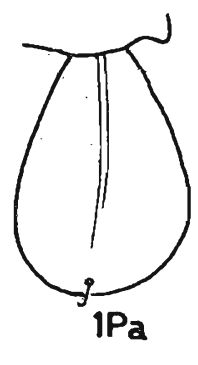

\section{FIG 4b}
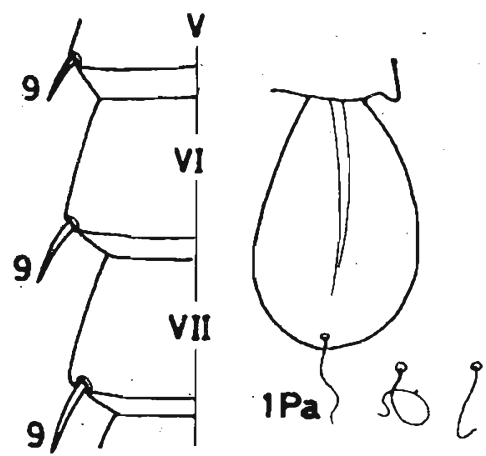

Figure 4a,b: Dorsal view of abdominal segments V-VII to show seta 9-V-VII, and of paddle to show seta 1-Pa.

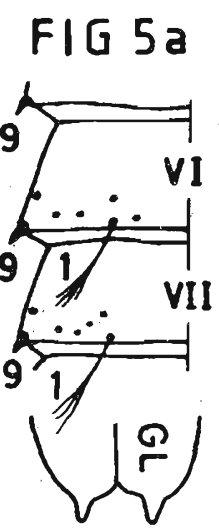

Figure. 5a,b: Dorsal view of segments VI-VIII to show seta 1-VI-VII, and ventral view of male genital lobe.

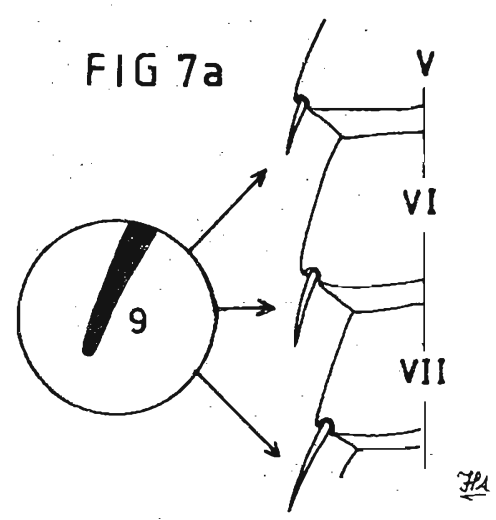

FIG 6a

FIG 6b
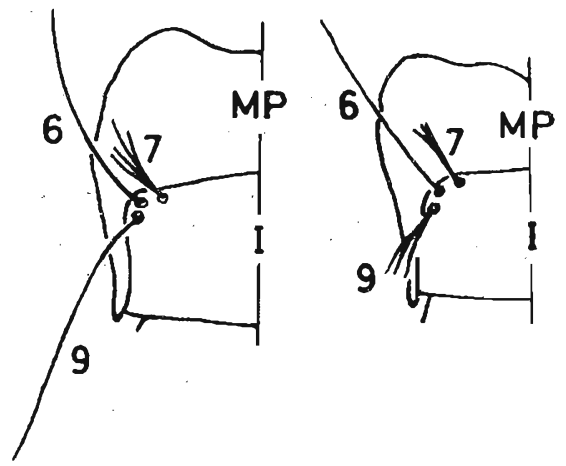

Figure. 6a,b: Dorsal view of abdominal segment I, to show seta 9-1.

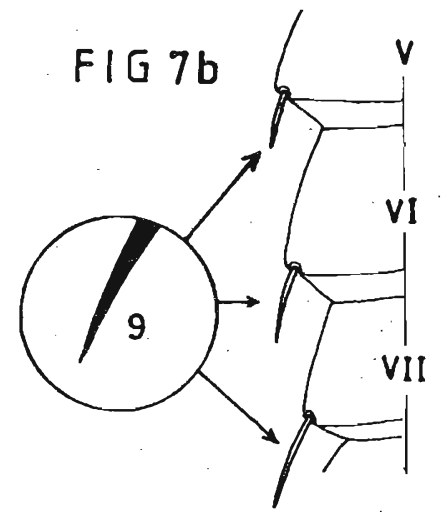

Figure. 7a,b: Dorsal view of abdominal segments V-VII, to show seta 9-V-VII. 


\section{FIG 8 a}

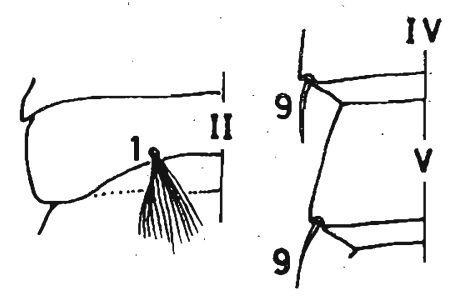

FIG $8 b$

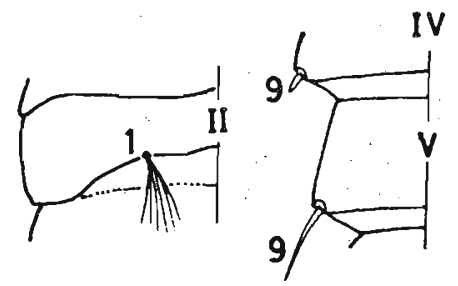

Figure. 8a,b: Dorsal view of abdominal segments II and IV.V, to show seta 1-II and 9-IV-V, respectively.

\section{FIG 9a}

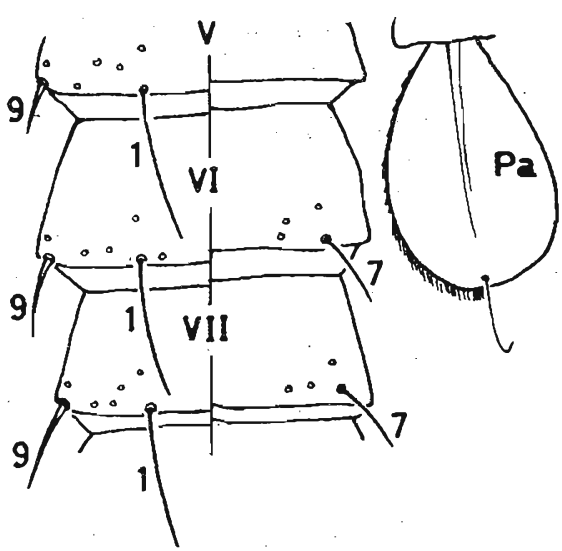

FIG $9 b$

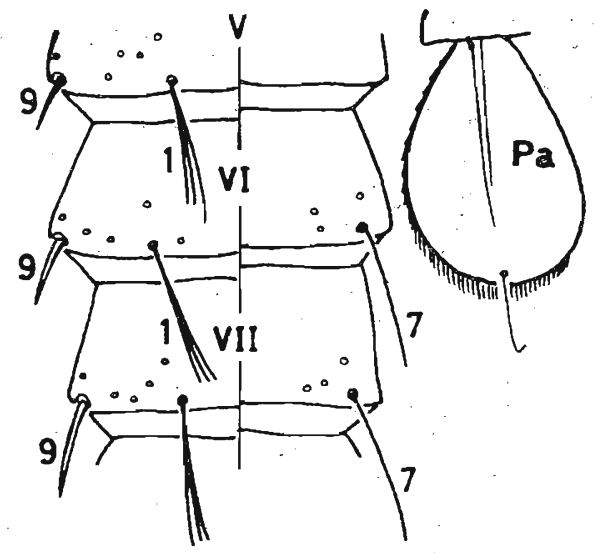

Figure. 9a,b: Dorsal (left) and ventral (right) view of abdominal segments V-VII to show seta 1,7,9-V.VII, and dorsal view of paddle to show distribution of fringe spicules.

\section{FIG 10a}

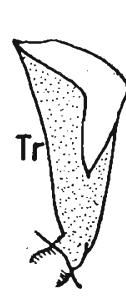

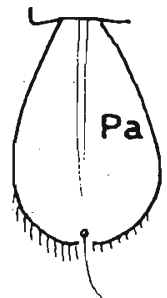

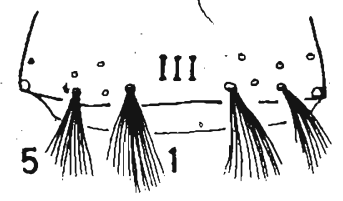

製

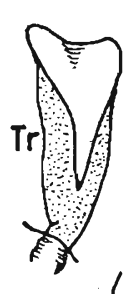

FIG 10b
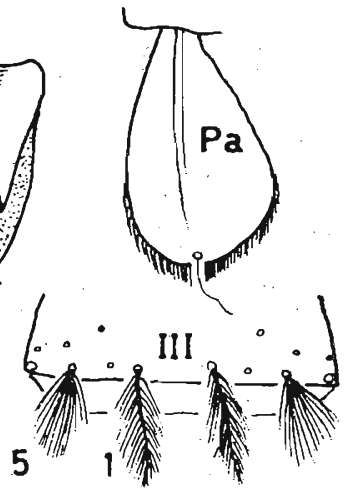

Figure. 10a,b: Lateral view of trumpet to show shape of pinna, dorsal view of paddle to show distribution of fringe spicules, and dorsal view of abdominal segment III to show seta 1,5-III. 
FIG 11a

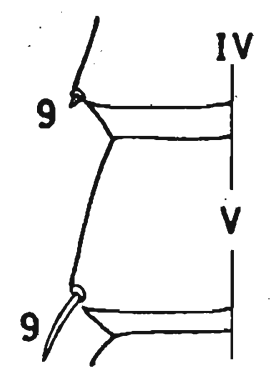

FIG $11 b$

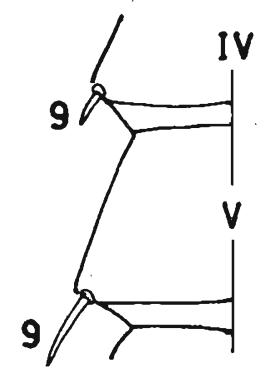

Figure 11a,b: Dorsal view of abdominal segments IV,V to show seta 9-IV,V.
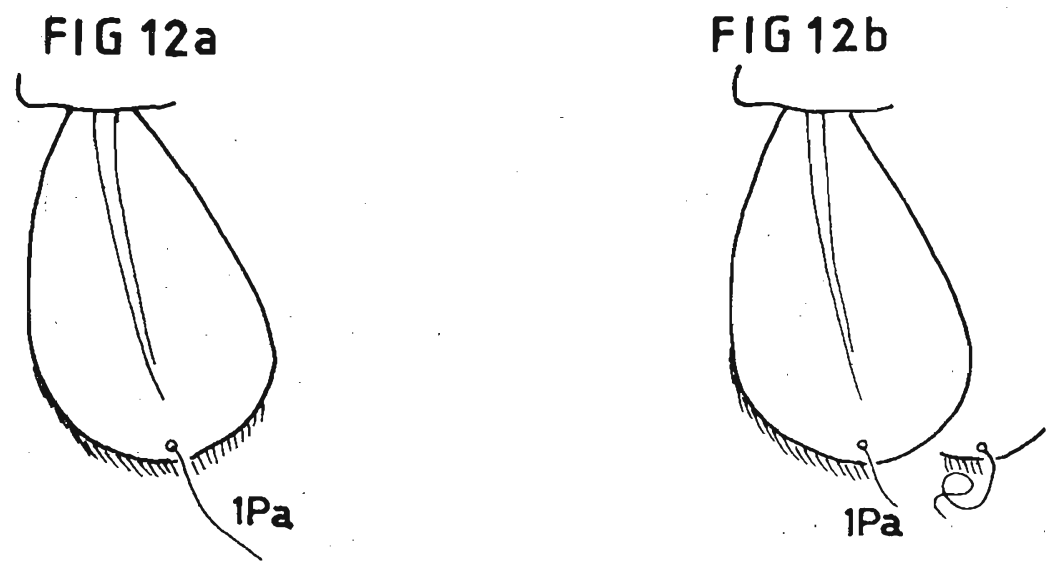

Figure 12a,b: Dorsal view of paddle to show seta 1-Pa and distribution of fringe spicules.

FIG 13a

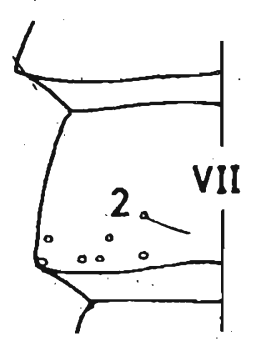

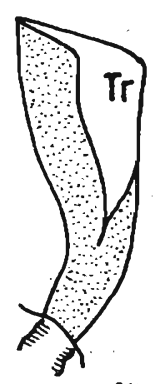

FPA
FIG 13b

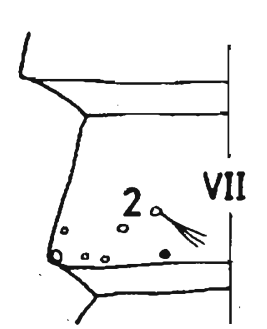

Figure 13a,b: Dorsal view of abdominal segment VII to show seta 2-VII, and lateral view of trumpet to show relative meatal length. 
FIG $14 a$
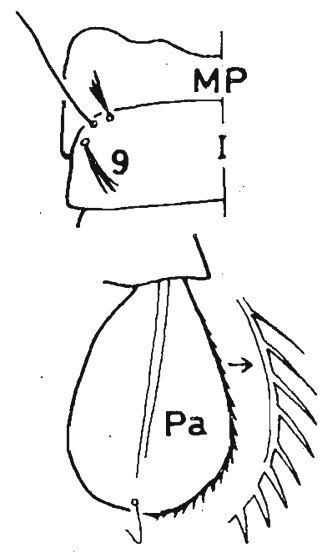

FIG $14 b$
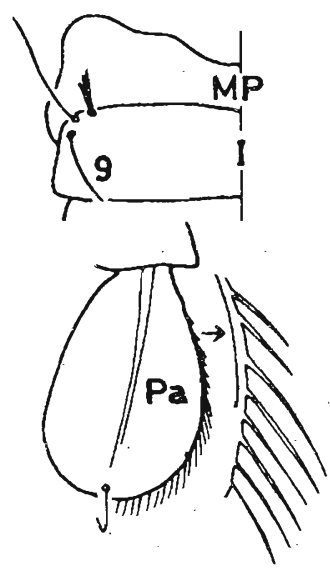

FIG 15a

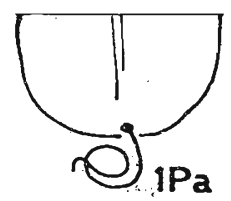

FIG 15b

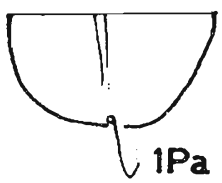

Figure 14a,b: Dorsal view of abdominal segment I to show seta 9-I, and of paddle to show fringe

Figure 15a,b: Dorsal view of paddle to show seta 1-Pa. spicules.

FIG $16 a$

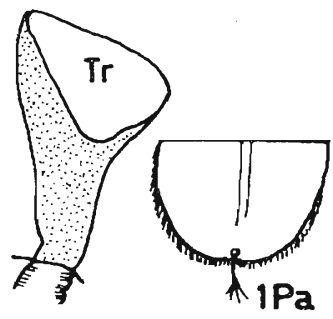

FIG 16b

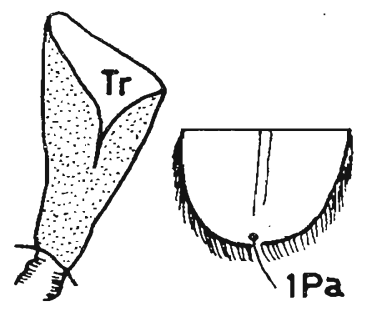

Figure 16a,b: Lateral view of trumpet to show meatal cleft, and dorsal view of paddle to show seta 1-Pa.

FIG 17a

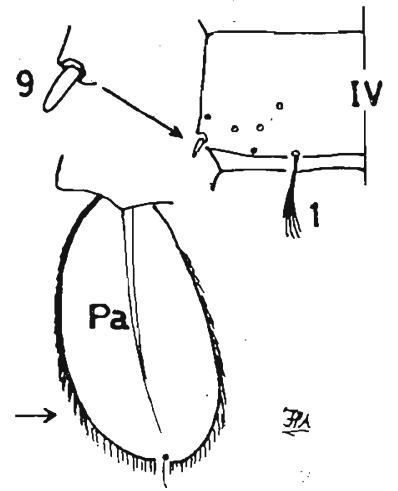

FIG $17 \mathrm{~b}$

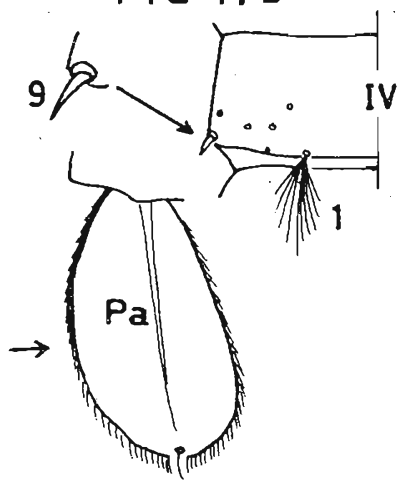

Figure 17a,b: Dorsal view of abdominal segment IV to show seta 9-IV, and of paddle to show refractile border. 
FIG 18a
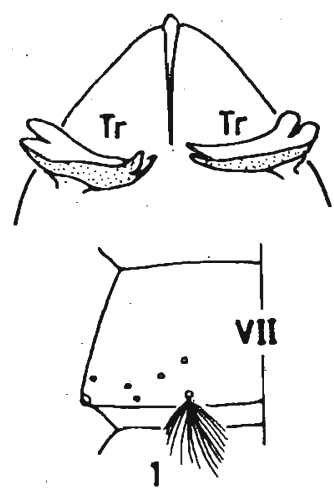

FIG 18b

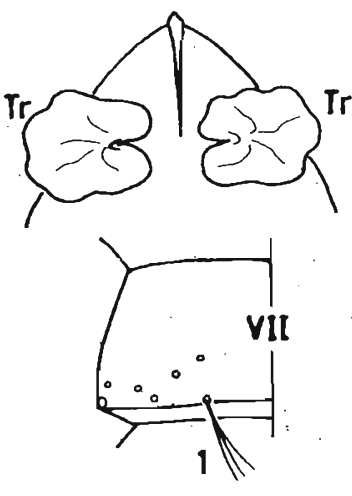

Figure 18a,b: Dorsal view of trumpets to show transverse and expanded nature, and of abdominal segment VII to show seta 1-VII.
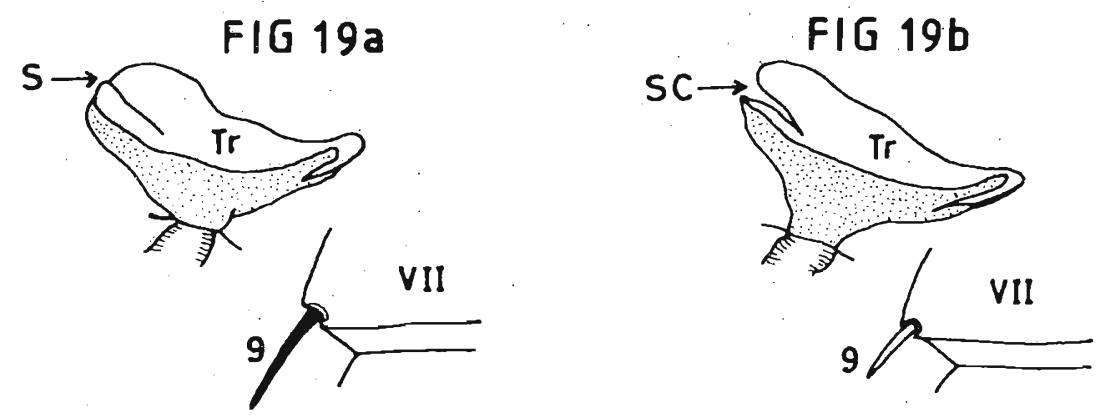

Figure 19a,b: Lateral view of trumpet to show nature of secondary cleft, and dorsal view of abdominal segment VII to show seta 9-VII.

FIG 20a

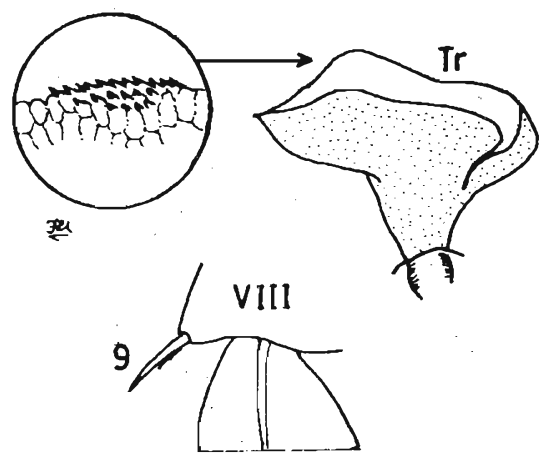

FIG 20b

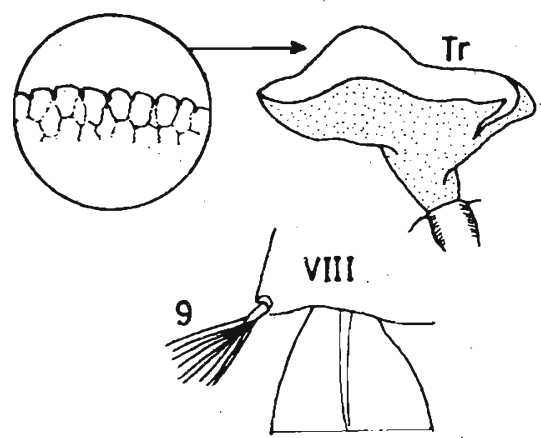

Figure 20a,b: Lateral view of trumpet to show nature of rim, and dorsal view of abdominal segment VIII to show seta 9-VIII. 


\section{NOTES ON THE KEY}

1. Much of the emphasis in the present key is on characters of the pupal trumpet, paddle, and the more prominent abdominal setae which can be visualized without too much difficulty even on whole pupae. In most instances, however, the magnification provided by dissecting microscopes will be insufficient, and it will be necessary to make a temporary mount of the pupae on microscopical slides and view at magnifications upto $100 \mathrm{x}$ under a transmittedlight microscope for a definite identification to be made.

2. The key does not include all possible characters useful in identifications, as this would make it unwieldy and time consuming to use. The characters selected for use in the key provide the most rapid and unambiguous means of separating the different species. Additional characters that can be used in the separation of some species pairs are listed below.

3. The pupae of An. elegans and An. tessellatus have not been separated previously. The characters used in the key (key step 5) are based on the examination of Sri Lankan material of both species. Whilst An. elegans reportedly occurs only in South India outside of Sri Lanka, An. tessellatus is widespread throughout the Oriental region and the variability in its pupal characters on a regional scale is unknown. Thus, the characters used in the key should be regarded as provisional, and applicable only to the local populations of these two species.

4. The separation of An. subpictus and An. vagus pupae (key step 7) should be regarded as provisional as it is based on a single character seen in Sri Lankan material. Reid ${ }^{3}$ used the length and branching of seta 6-IV (short and double in An. subpictus, long and single in An. vagus) and the nature of the lower paddle spicules (tips hooked in An. subpictus, not hooked in An. vagus) to separate the two species.

However, Reid's keys were based on descriptions and/or the examination of very few specimens of these species from the Southeast Asian region. I have found the appearance of the paddle spicule tips and the length/branching of seta 6-IV to be unreliable for the separation of Sri Lankan An. subpictus and An. vagus. Indeed, contrary to Reid, most local An. subpictus have 6-IV single, and An.vagus have seta 6-IV double. In the present work, seta 9-V-VII (blunt tip in An. subpictus, sharply pointed tip in An. vagus) has been used to separate the two species, based on an examination of local material.

5. An. interruptus can be separated from the aitkenii group (key step 16) on the basis of the following additional characters: seta 9-V-VII hooked at tip, seta 5V-VII with long, strong axis and short branches along its length, and seta 1-VVII very small and weak in An. interruptus, contrasted with seta 9-V-VII not hooked at tip, seta 5-V-VII with weaker axis and long branches along its length, and seta $1-$ V-VII well developed in the aitkenii group. ${ }^{1}$ 
6. An. barbumbrosus and An. barbirostris can be separated on the basis of an additional character at key step 19. The sum of the branches of both setae 5-III less than 30 in An barbumbrosuis, whilst this sum is grea ter than 30 in An. barbirostris. ${ }^{1}$

7. An. peditaeniatus and An. nigerrimus can be separated by an additional character at key step 20. An. peditaeniatus has seta 1-V with 1-6 branches whilst An. nigerrimus has seta $1-\mathrm{V}$ with 8 or more branches. ${ }^{1}$

\section{Acknowledgement}

I thank Dr. Manthri Ramasamy of the Institute of Fundamental Studies (IFS), Kandy, for providing specimens of An. tessellatus.

\section{References}

1. Harrison B.A. \& Scanlon J.E. (1975). Medical entomology studies - II. The subgenus Anopheles in Thailand (Diptera: Culicidae). Contributions of the American Entomological Institute 12: 1-307.

2. Peiris J.S.M., Amerasinghe P.H., Amerasinghe F.P., Calisher C.H., Perera L.P., Arunagiri C.K., Munasingha N.B. \& Karunaratne S.H.P.P. (1994). Viruses isolated from mosquitoes collected in Sri Lanka. American Journal of Tropical Medicine \& Hygiene 51(2): 154-161.

3. Reid J.A. (1968). Anopheline mosquitoes of Malaya and Borneo. Studies from the Institute for Medical Research Malaysia. Government of Malaysia. No.31. 903pp.

4. Amerasinghe F.P., Amerasinghe P.H., Peiris J.S.M. \& Wirtz R.A. (1991). Anopheline ecology and malaria infection during the irrigation development of an area of the Mahaweli Project, Sri Lanka. American Journal of Tropical Medicine \& Hygiene 45: 226-235.

5. Mendis C., Herath P.R.J., Rajakaruna J., Weerasinghe S., Gamage-Mendis A.C., Mendis K.N. \& de Zoysa A.P.K. (1992). Method to estimate relative transmission efficiencies of Anopheles species (Diptera: Culicidae) in human malaria transmission. Journal of Medical Entomology 29: 188-196.

6. Ramasamy R., De Alwis R., Wijesundere A. \& Ramasamy M.S. (1992). Malaria transmission at a new irrigation project in Sri Lanka: the emergence of Anopheles annularis as a major vector. American Journal of Tropical Medicine and Hygiene 47: 547-553.

7. Amerasinghe F.P. (1990). A guide to the identification of the anopheline mosquitoes of Sri Lanka. I. Adults. Ceylon Journal of Science (Biological Science) 21: 1-16. 
8. Amerasinghe F.P. (1992). A guide to the identification of the anopheline mosquitoes of Sri Lanka. II. Larvae. Ceylon Journal of Science (Biological Science) 22: 1-13.

9. Christophers S.R. (1933). The Fauna of British India, including Ceylon and Burma. Diptera. Vol. IV. Family Culicidae. Tribe Anophelini. Taylor \& Francis, London. 371pp.

10. Harrison B.A. (1980). Medical entomology studies - XIII. The Myzomyia series of Anopheles (Cellia) in Thailand, with emphasis on intra-interspecific variations (Diptera: Culicidae). Contributions of the American Entomological Institute 17: 1-195.

11. Mendis K.N., Ihalamulla R.L., Peyton E.L. \& Nanayakkara S. (1983). Biology and description of the larva and pupa of Anopheles (Cellia) elegans James (1903). Mosquito Systematics 15: 318-324.

12. Kulasekera V.L., Harrison B.A. \& Amerasinghe F.P. (1988). Anopheles (Anopheles) peytoni n.sp., the "An. insulaeflorum" auct. from Sri Lanka (Diptera : Culicidae). Mosquito Systematics 20: 302-316.

13. Harbach R.E. \& Knight K.L. (1980). Taxonomists' Glossary of Mosquito Anatomy. Plexus Publishing Inc.. New Jersey. 415 pp. 